\title{
Transarterial Alcohol-Lipiodol Therapy in Patients with Hepatocellular Carcinoma Using Low Alcohol Concentrations
}

\section{Transarterielle Alkohol-Lipiodol-Therapie bei Patienten mit hepatozellulärem Karzinom unter Verwendung niedriger Alkoholkonzentrationen}

Authors

Affiliations
F. Mohné1, C. Meyer ${ }^{1}$, C. K. Kuhl², C. C. Pieper ${ }^{1}$, H. H. Schild ${ }^{1}$

Department of Radiology, University Hospital Bonn, Germany

Department of Diagnostic and Interventional Radiology, University Hospital RWTH Aachen, Germany

\section{Key words}

- hepatocellular carcinoma (HCC)

- interventional procedures

- transarterial therapy

- liver

Q alcohol ablation received 20.12.2015 accepted 19.3.2016

\section{Bibliography}

DOI http://dx.doi.org/ 10.1055/s-0042-106305 Published online: 1.6.2016 Fortschr Röntgenstr 2016; 188: 676-683 @ Georg Thieme Verlag KG Stuttgart · New York . ISSN 1438-9029

\section{Correspondence \\ Dr. Florian Mohne}

Department of Radiology, Rheinische Friedrich Wilhelms Universität Bonn

Sigmund-Freud-Straße 25 53127 Bonn

Germany

Tel.: ++49/2 28/28715237 Fax: ++49/2 28/28719083

florian.mohne@ukb.uni-bonn. de

\section{Abstract \\ $\nabla$}

Purpose: To evaluate transarterial alcohol-lipiodol therapy (TAL) with low concentrations of alcohol for the treatment of hepatocellular carcinoma (HCC).

Materials and Methods: 17 patients (69.3 $\pm 10.7 \mathrm{a}, 13$ male, 4 female) with previously untreated HCC (tumor diameter: $7.7 \pm 5.8 \mathrm{~cm}$ ), who underwent 20 transarterial alcohol-lipiodol injections, were evaluated retrospectively. 14 patients had HCC with coexistent cirrhosis (Child-A $n=9$, Child-B $n=4$, Child-C $\mathrm{n}=1$ ). 9 patients presented an Okuda stage I, 7 patients an Okuda stage II and 1 patient an Okuda stage III. Infiltration of the portal vein was seen in 3 patients.

Results: 15 patients underwent TAL with an alcohol:lipiodol ratio of $1: 2$, another one with a ratio of $1: 3$ and yet another one with a ratio of $1: 5$. The median survival was 23 months, and the 1-year and 2-year survival rates were $62.7 \%$ and $31.4 \%$, respectively. The median survival of patients with HCC $<7.5 \mathrm{~cm}(\mathrm{n}=10)$ was 25 months and significantly ( $\mathrm{p}=0.009$ ) higher than for patients with HCC $\geq 7.5 \mathrm{~cm}$ ( $\mathrm{n}=7 ; 3$ months). Tumor diameters $\geq 7.5 \mathrm{~cm}$ were associated with worse lipiodol-contrasting of HCC. Intrainterventional side effects were only feelings of slight abdominal pressure in 2 of 20 interventions. Postinterventional, mild side effects were observed after 3 interventions (abdominal pain $n=1$, thoracic pain $n=1$, fever $n=1$ ). Serious complications were not observed, in particular there was no decompensation of liver cirrhosis.

Conclusion: TAL with low concentrations of alcohol was a safe and effective treatment in our cohort in spite of extensive tumors and impaired liver function. TAL could be a treatment option for patients who cannot receive other therapies (e.g. TACE, RFA) because of their advanced tumor disease, liver cirrhosis or other contraindications.

Key points:

- TAL can be performed safely in advanced tumor disease and liver cirrhosis

Citation Format:

- Mohné F, Meyer C, Kuhl CK et al. Transarterial Alcohol-Lipiodol Therapy in Patients with Hepatocellular Carcinoma Using Low Alcohol Concentrations. Fortschr Röntgenstr 2016; 188: 676-683

\section{Zusammenfassung}

Ziel: Evaluation der transarteriellen Alkohol-Lipiodol-Therapie (TAL) mit geringer Alkoholkonzentration zur Behandlung des hepatozellulären Karzinoms (HCC).

Material und Methoden: Retrospektiv ausgewertet wurden 17 Patienten $(69,3 \pm 10,7 a$; 13 männlich, 4 weiblich) mit bislang unbehandeltem HCC (Tumorgröße 7,7 $\pm 5,8 \mathrm{~cm}$ ), die 20 transarterielle Alkohol-Lipiodol-Injektionen erhielten. Bei 14 Patienten entstand das HCC auf dem Boden einer Leberzirrhose (Child A $n=9$, Child B $n=4$, Child C $\mathrm{n}=1$ ). 9 Patienten wiesen ein Okuda-Stadium I, 7 ein Okuda-Stadium II, 1 Patient ein Okuda-Stadium III auf. Eine Pfortaderinfiltration bestand bei 3 Patienten.

Ergebnisse: 15 Patienten erhielten die TAL mit Alkohol:Lipiodol-Verhältnissen von $1: 2$, je ein weiterer Patient mit einem Verhältnis von 1:3 bzw. 1:5. Das mediane Überleben betrug 23 Monate, 1-Jahres- bzw. 2-Jahres-Überlebensraten betrugen 62,7 bzw. $31,4 \%$. Patienten mit HCC $<7,5 \mathrm{~cm}$ ( $n=10)$ überlebten im Median 25 Monate und damit signifikant $(p=0,009)$ länger als Patienten mit $\mathrm{HCC} \geq 7,5 \mathrm{~cm}$ ( $\mathrm{n}=7 ; 3$ Monate). Tumordiameter $\geq 7,5 \mathrm{~cm}$ waren mit schlechteren Lipiodol-Kon- 
trastierungen des HCC assoziiert. Intrainterventionelle Nebenwirkungen waren lediglich ein leichtes, abdominelles Druckgefühl in 2 von 20 Interventionen. Postinterventionelle, gering ausgeprägte Nebenwirkungen traten nach 3 Interventionen auf (abdominelle Schmerzen $n=1$, thorakale Schmerzen $n=1$, Fieber $\mathrm{n}=1$ ). Schwerwiegende Komplikationen wurden nicht beobachtet, insbesondere fand sich keine Dekompensation einer Leberzirrhose.

Schlussfolgerung: Die TAL mit niedriger Alkoholkonzentration war in unserem Kollektiv auch bei ausgedehnten Tumoren und eingeschränkter Leberfunktion effektiv und sicher. Für Patienten, die anderen Therapieformen (z.B. TACE, RFA) aufgrund fortgeschrittener Tumorerkrankung, Leberzirrhose oder anderer Kontraindikationen nicht zugänglich sind, kann die TAL eine durchführbare Therapieoption sein.

\section{Introduction}

Locoregional therapies represent an important treatment option for patients with inoperable hepatocellular carcinoma (HCC). Transarterial treatment methods include established conventional chemoembolization (TACE) as well as bland embolization, variants of TACE with application of loaded beads and embolization with radioactive particles (radioembolization, selective internal radiotherapy, SIRT) [1].

Transarterial treatments with injection of a highly concentrated alcohol-lipiodol mixture were already reported at the beginning of the $1990 \mathrm{~s}$ [2]. However, since this mixture resulted in early [3]/(too) fast vascular occlusion, the tumor to be treated was often only incompletely reached. Modification of the method with the use of a lower alcohol concentration was described in 2008 with promising results [4]. To date, there have only been a few studies regarding this therapeutic method. Therefore, we will report our experiences in the following.

\section{Materials and Methods}

$\nabla$

The retrospective study included HCC patients who underwent transarterial alcohol-lipiodol therapy (TAL) between 10/30/2006 and 4/1/2013.

The indication for TAL was made in interdisciplinary tumor boards when due to the number, position, size, or characteristics of the HCC (e.g. infiltrative growth):

> An inoperable HCC was present,

$\checkmark$ percutaneous radiofrequency ablation (RFA) was not possible, and

$\checkmark$ there were contraindications for TACE, or

the patient explicitly requested a treatment with minimal side effects as was expected to be the case with TAL due to the lack of the use of cytostatic/hepatotoxic medications and embolization materials.

The technical requirement for performing TAL was blood supply to the HCC that was clearly identifiable on angiography and allowed selective therapy.

Patients who had already undergone other locoregional therapies or in whom a combination with other treatment methods was planned before TAL were not taken into consideration in this study.

\section{Data}

Demographic data (age, sex) and disease-related data (liver cirrhosis, Child stage of the cirrhosis, serum bilirubin level prior to therapy) were taken from the patient files and medical reports.

Based on preinterventional imaging (contrast-enhanced CT and MRI scans), the tumor size (maximum diameter) was determined and additional factors, such as the presence of a multifocal tumor, Okuda stage, and portal vein infiltration, were recorded.

\section{Transarterial alcohol-lipiodol injection (TAL) technique}

Prior to the intervention, patients received an antiemetic (8 mg ondansetron) and an analgesic (50-100 mg pethidine, depending on body weight) intravenously.

Angiographic imaging of the local perfusion conditions was initially performed in all patients. The vessels supplying the tumor were then probed and visualized with a microcatheter (e.g. 2.5F Renegade, Boston Scientific Corporation, Natick, MA, USA) as selectively as possible (i.e., at least on the subsegment level, but typically more selectively even for multifocal HCCs).

Treatment was then administered by applying an alcohol-lipiodol mixture ( $\bullet$ Fig. 1 ). Injection was performed under fluoroscopy until either portal venous branches became visible or perfusion stasis occurred.

After removal of the catheter material and compression or occlusion of the puncture site with a suture system, an unenhanced CT scan of the upper abdomen was conducted to record and evaluate the intratumoral lipiodol enhancement. Enhancement was evaluated in $20 \%$ increments, i. e., $20 \%, 40 \%$, etc. (in relation to tumor volume).

Side effects were recorded periinterventionally and over the further course.

\section{Imaging}

CT and MRI control scans were performed after four weeks and - if no early arterial, intratumoral contrast enhancement as an indication of active tumor tissue was seen - after twelve weeks and then every three months. If intratumoral contrast enhancement was still visible on the first control scan after four weeks, a second TAL was performed in an attempt to deactivate the enhanced remaining vital tumor tissue.

The CT units used for image acquisition were multidetector scanners (Mx8000 IDT 16 and Brilliance 64, Philips Medical Systems DMC, Hamburg, Germany). Contrast-enhanced scans were performed using the multiphase spiral technique following automatic intravenous bolus injection of $100 \mathrm{ml}$ iopromide (Ultravist 300, Bayer HealthCare AG, Leverkusen, Germany) and $50 \mathrm{ml}$ of a sodium chloride solution. Image acquisition occurred in an early arterial and in a portal venous phase. The primary slice thickness reconstruction was $2 \mathrm{~mm}$ with an increment of $1 \mathrm{~mm}$ for both unenhanced scans and contrast-enhanced CT scans.

MRI scans were performed on $1.5 \mathrm{~T}$ and $3 \mathrm{~T}$ units (Intera 1.5 T and Achieva 3.0 T, Philips Medical Systems DMC, Hamburg, Germany). Dynamic T1-weighted sequences and T2weighted fat-suppressed sequences were acquired. The contrast agents that were used were gadobutrol (gadovist, Bayer HealthCare AG, Leverkusen, Germany; $8 \mathrm{ml}$ ) and ga- 

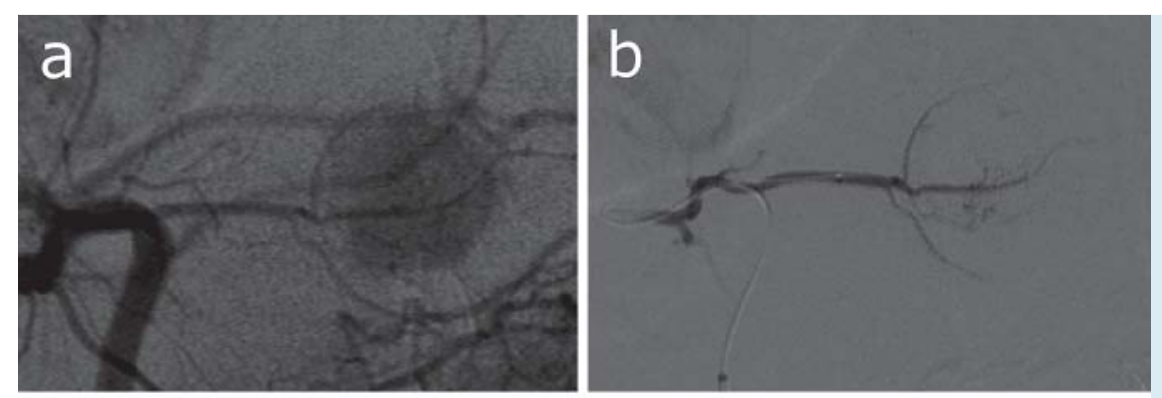

Fig. 1 Angiographic image of one manifestation of a patient with multifocal hepatocellular carcinoma before transarterial alcohol-lipiodol injection (TAL) $\mathbf{a}$, at the beginning of TAL $\mathbf{b}$, during TAL $\mathbf{c}$ and angiographic control image after TAL d.
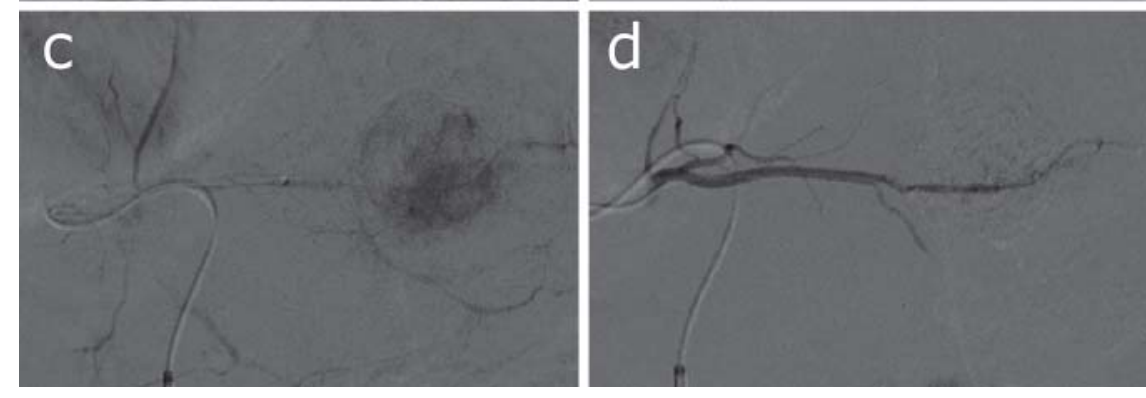

doxetat (gadolinium-EOB-DTPA, Primovist, Bayer HealthCare AG, Leverkusen, Germany; $8 \mathrm{ml}$ ).

\section{Statistical evaluation}

Survival time analyses were performed according to the Kaplan-Meier method. Survival times relate to the interval between TAL and death. Patients with any therapy change (not initially planned) and one patient who died of TAL- and HCCindependent sepsis (sepsis due to infected total hip endoprosthesis) were censored at the corresponding time points. The variable time-to-progression (TTP) was defined as the time interval between TAL and tumor progression with tumor progression being defined according to mRECIST criteria [5]. Patients who underwent a therapy change due to incomplete TAL were censored in the calculation of TTP at the corresponding time points. The median survival is specified.

All statistical analyses were performed with SPSS 15.0 (SPSS Inc., Chicago, USA). The cumulative survival times of two groups were compared using the log-rank test. $\mathrm{p}<0.05$ was defined as significant. The disease course of the patients was visualized via GraphPad Prism for Windows 5 (GraphPad Software Inc., La Jolla, California, USA)

Continuous variables were given as median values and mean values with the simple standard deviation.

\section{Results}

$\nabla$

TAL was performed in 17 patients ( 13 male, 4 female) with an average age of $69.3 \pm 10.7$ years $(46-85 a)$. The average tumor size was $7.7 \pm 5.8 \mathrm{~cm}(2.2-26 \mathrm{~cm})$. Patients with HCC $<5 \mathrm{~cm}(\mathrm{n}=6)$ had

$>$ multifocal HCC $>3 \mathrm{~cm}(\mathrm{n}=2)$,

- multifocal HCC with $>3$ manifestations $(\mathrm{n}=1)$,

$\checkmark$ diffuse-infiltrative HCC $(n=2)$ or

> contraindications for anesthesia $(\mathrm{n}=1)$ and were assessed in the tumor board as inoperable and not suitable for RFA so that transarterial therapy was performed.
The applied total amount of the alcohol-lipiodol mixture was $4.5-69 \mathrm{ml}$. The mixture ratio of alcohol to lipiodol was $1: 2$ in 15 patients, $1: 3$ in 1 patient and 1:5 in another patient. The last two patients had HCC with only faint arterial contrast enhancement on angiography. This aspect was interpreted as an indication of possible still pronounced portal venous tumor perfusion. Based on the assumption that portal venous tumor vessels would be better reached with lower alcohol concentrations in the therapeutic emulsion, a more diluted alcohol was used for therapy.

9 patients were in Okuda stage I, 7 were in Okuda stage II and 1 was in Okuda stage III. Child-A cirrhosis was present in 9 patients, Child-B cirrhosis in 4 patients and Child-C cirrhosis in 1 patient. The 3 patients with the largest HCC manifestations $(12.4 \mathrm{~cm}, 13 \mathrm{~cm}$ and $26 \mathrm{~cm}$ ) had HCC infiltration of the portal vein (survival 1, 2, and 3 months, respectively). Details of the patient population are provided in 0 Table 1.

The median survival of the total population was 23 months ( $\bullet$ Fig. 2). The median survival of patients was 23 months in Okuda stage I and 12 months in Okuda stage II. The patient in Okuda stage III survived 3 months ( $p=0.006$; $\odot$ Fig. 3 ).

Of the total of 17 patients

- 12 were treated via TAL. 2 of the 12 patients had persistent contrast enhancement on the control scan after TAL but did not want to undergo further treatment attempts because of the expected poor prognosis due to the advanced underlying disease (Child-C cirrhosis, Okuda stage II and Child-B cirrhosis, Okuda stage III, portal vein infiltration). After initially successful TAL, 3 additional patients required subsequent therapy ("secondary therapy", 0 Table 2) in the later disease course due to tumor progression. These 3 patients as well as 1 patient who died from complications of an infected total hip endoprosthesis (sepsis) and not as a result of the underlying disease were censored in the survival time analyses at the corresponding time points.

5 patients had persistent intratumoral contrast enhancement and thus incomplete TAL on the control scan four weeks after TAL. Completion attempts via a second TAL procedure were performed in 3 patients but were unsuc- 
Table 1 Demographics of the patient population before therapy.

\begin{tabular}{|l|l|}
\hline number of patients & 17 \\
\hline age & \\
\hline - median & $73 \mathrm{a}$ \\
\hline - range & $46-85 \mathrm{a}$ \\
\hline - mean $\pm \mathrm{s}$ & $69.3 \pm 10.7 \mathrm{a}$ \\
\hline sex & \\
\hline - male & $13 / 17(76.5 \%)$ \\
\hline - female & $4 / 17(23.5 \%)$ \\
\hline okuda stage & \\
\hline - stage I & $9 / 17(52.9 \%)$ \\
\hline - stage II & $7 / 17(41.2 \%)$ \\
\hline - stage III & $1 / 17(5.9 \%)$ \\
\hline tumour diameter & \\
\hline - median & $7.0 \mathrm{~cm}$ \\
\hline - range & $2.2-26.0 \mathrm{~cm}$ \\
\hline - mean $\pm \mathrm{s}$ & $7.7 \pm 5.8 \mathrm{~cm}$ \\
\hline tumour manifestation & \\
\hline - solitary & $9 / 17(52.9 \%)$ \\
\hline - multiple & $8 / 17(47.1 \%)$ \\
\hline infiltration of portal vein & \\
\hline - yes & $3 / 17(17.6 \%)$ \\
\hline - no & $14 / 17(82.4 \%)$ \\
\hline liver cirrhosis & $14 / 17(82.4 \%)$ \\
\hline etiology of liver cirrhosis & \\
\hline - viral & $4(23.5 \%)$ \\
\hline - ethyl toxic & $4(23.5 \%)$ \\
\hline - cryptogenic & $6(35.4 \%)$ \\
\hline child stage & $9(52.9 \%)$ \\
\hline - child A & $4(23.5 \%)$ \\
\hline - child B & $1(6 \%)$ \\
\hline - child C & $0.9 \mathrm{mg} / \mathrm{dl}$ \\
\hline serum bilirubin level & $0.3-2.8 \mathrm{mg} / \mathrm{dl}$ \\
\hline - median & $1.2 \pm 0.8 \mathrm{mg} / \mathrm{dl}$ \\
\hline - range & \\
\hline - mean $\pm s$ & standard deviation; all percentages in () are related to the overall collective $(\mathrm{n}=17)$. \\
\hline
\end{tabular}

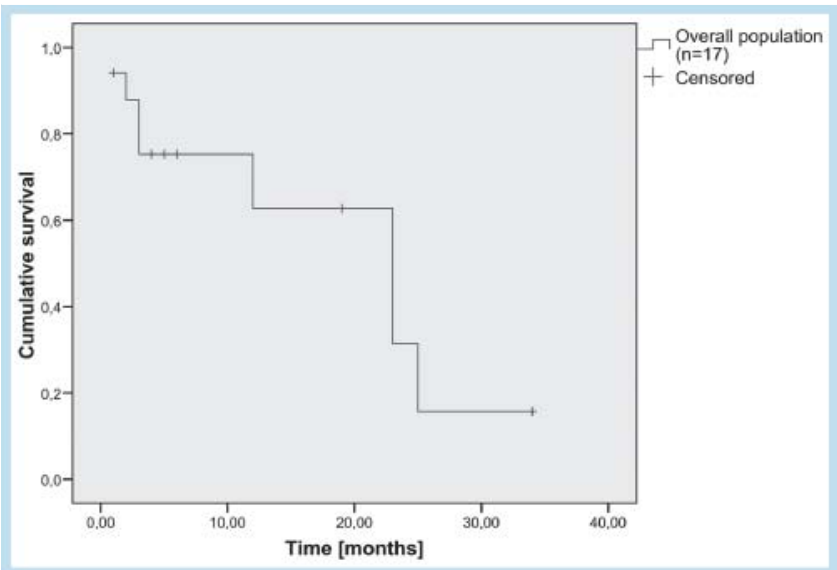

Fig. 2 Survival of patients treated with transarterial alcohol-lipiodol therapy (TAL; $n=17)$. The median survival was 23 months, and the 1 -year and 2-year survival rates were $62.7 \%$ and $31.4 \%$, respectively. Two patients (both Okuda stage 1, unifocal HCC, tumor diameters $5 \mathrm{~cm}$ and $7 \mathrm{~cm}$ ) were alive at the end of the TAL observation period (34 months) and survived a further 18 and 19 months, respectively. They were censored because of a previous progression-associated therapy change.

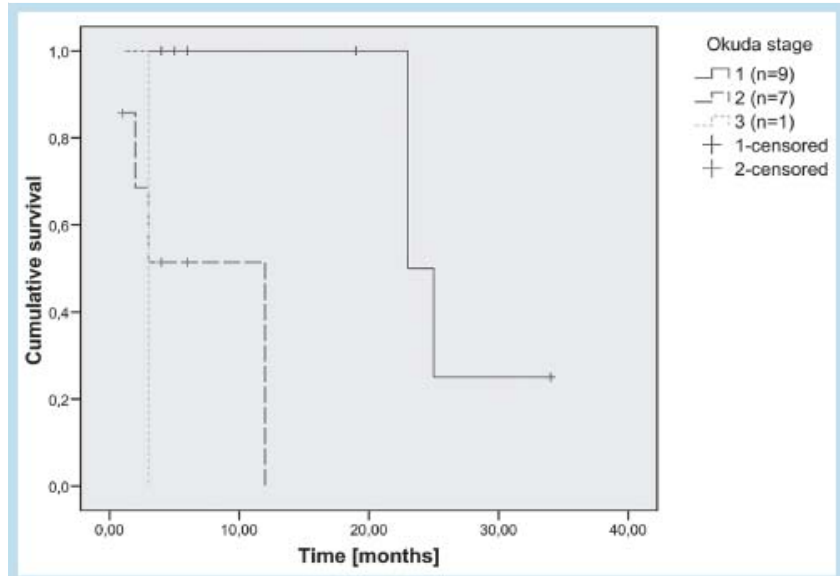

Fig. 3 Survival depending on Okuda stage after transarterial alcohol-lipiodol therapy (TAL). The median survival differs significantly $(p=0.006)$. It was 23 months in Okuda stage I $(n=9)$ and 12 months in Okuda stage II $(n=7)$. The patient with Okuda stage III died 3 months after alcohol-lipiodol therapy. 2 patients were alive at the end of the TAL observation period (34 months) and survived a further 18 and 19 months, respectively, but they were censored because of a previous progression-associated therapy change.

cessful. The reasons for the failure of TAL in these 5 patients were an AV shunt that could not be closed resulting in outflow of the therapeutic emulsion $(n=1)$, a caval tumor thrombosis that was only incompletely accessible $(n=1)$, and the inability to probe tumor vessels remaining open after TAL $(n=3)$. Subsequent therapies included systemic therapy via sorafenib in the case of the AV shunt, partial resection of the caval tumor thrombus and non-selective TACE in the remaining 3 patients. These patients were censored in the survival time curves with the start of the subsequent therapies.

- Fig. 4 shows an overview of the disease course of the patients. $\triangle$ Table 3 provides the treatment response according to mRECIST criteria. The preceding TAL procedure did not interfere with the implementation of secondary therapies in the case of tumor progression $(n=3)$ or subsequent therapies in the case of incomplete $\operatorname{TAL}(n=5)$ in a single case.

\section{Side effects and complications}

A feeling of light abdominal pressure was reported in only 2 of the 20 interventions and resolved spontaneously. Symptomatically treated abdominal pain, spontaneously resolving thoracic pain, and fever with no determined source were observed postinterventionally in one patient in each case.

Additional side effects or complications were not seen. In particular, there was no increase in or recurrence of ascites as a sign of decompensation of liver cirrhosis.

\section{Time-to-progression}

After successful TAL, tumor progression occurred in 6 patients in the further disease course. Secondary therapies were performed in 3 patients ( $\bullet$ Table 2 ). The remaining 3 patients were treated exclusively symptomatically. The reasons for not performing secondary therapies are specified in - Table 2. 
Table 2 Therapies and courses of disease for patients with progression of hepatocellular carcinoma after transarterial alcohol-lipiodol-therapy ( $n=6)$.

\begin{tabular}{|c|c|c|c|c|c|}
\hline patient & $\begin{array}{l}\text { number of lesions/ } \\
\text { localization }\end{array}$ & progression from & TाP (months) & secondary therapy & $\begin{array}{l}\text { survival after progression } \\
\text { (months) }\end{array}$ \\
\hline 1 & $2 / R(S 8,58)$ & P, I (S4), E & 4 & SIRT, ST & 15 \\
\hline 2 & $1 / R(S 8)$ & $\mathrm{E}, \mathrm{I}(\mathrm{S} 4, \mathrm{~S} 7)$ & 11 & TAL+TACE, TACE, ST & 41 \\
\hline 3 & $1 / L(S 4)$ & $\mathrm{P}$ & 34 & TAL, TAL+TACE, TACE & 19 \\
\hline 4 & $1 / L(S 4)$ & $E$ & 1 & - & 1 \\
\hline 5 & $2 / R(S 5, S 6)$ & $P, I(2 / 3)$ & 9 & - & 3 \\
\hline 6 & $1 / R(S 7)$ & I (S4) & 17 & - & 6 \\
\hline
\end{tabular}

TTP = time-to-progression; Localisation: $R=$ right hepatic lobe, $L=$ left hepatic lobe, ()$=$ segment of liver with the primary tumour; Progression: $P=$ progression of primary tumour, I = progression with new, intrahepatic tumours, () = localization of new, intrahepatic tumours, E = new, extrahepatic tumours; Secondary therapies: SIRT = Selective Interne Radiotherapy; ST = systemic therapy with Sorafenib; TAL = transarterial alcohol-lipiodol-therapy; TACE = transarterial chemoembolization; Causes to waive consecutive treatment in patients 4 - 6: Patient 4: poor general condition, progression with peritoneal carcinosis; patient 5: slight tumour progression and decision to watchful wait; patient 6: intercurrent, advanced Parkinson-disease and NYHA 3 cardiac insufficiency.

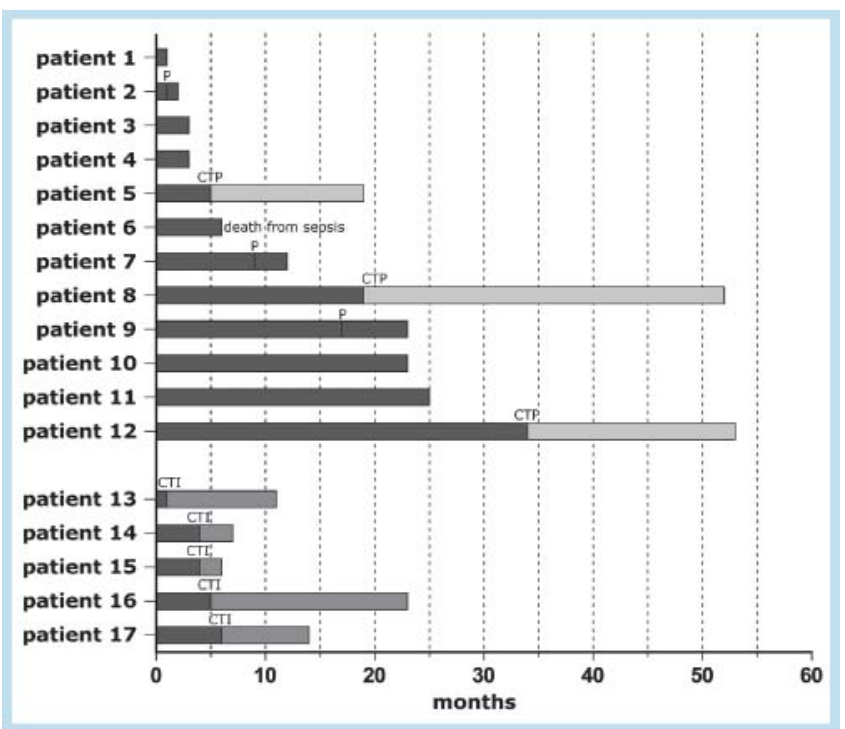

Fig. 4 Survival and disease course of the entire group of patients after the beginning of transarterial alcohol-lipiodol therapy (TAL). $\mathrm{P}=$ tumor progression without subsequent therapy, $\mathrm{CTP}=$ change in therapy due to tumor progression, $\mathrm{CTI}=$ change in therapy because of incomplete or failed TAL.

Table 3 Best overall response of 17 patients treated with transarterial alcohol-lipiodol-therapy (TAL) in accordance to mRECIST criteria [5].

\begin{tabular}{|c|c|c|c|c|c|}
\hline $\begin{array}{l}\text { best overall } \\
\text { response }\end{array}$ & CR & PR & SD & PD & D \\
\hline $\mathrm{n}$ & 8 & 3 & 4 & 1 & 1 \\
\hline
\end{tabular}

$\mathrm{CR}=$ complete response, $\mathrm{PR}=$ partial response, $\mathrm{SD}=$ stable disease, $\mathrm{PD}=$ progressive disease, $D=$ death before imaging. Therapy was changed due to an incomplete TAL for all three patients with PR and for two patients with SD. Two more patients with SD and thus incomplete TAL wanted no further therapy attempts due to an advanced disease with expected poor prognosis (Child C cirrhosis, Okuda stage II respectively Child B cirrhosis, Okuda stage III, portal vein infiltration). The patient with PD had a new peritoneal carcinosis in postinterventional control imaging 1 month after TAL. One patient (Okuda stage II, portal vein infiltration) died one month after TAL without control imaging.

The median time-to-progression was 17 months (1-34 months; 0 Fig. 5).

3 patients had stable primary tumors with progression resulting from intrahepatic metastases $(n=1)$, extrahepatic metastases $(n=1)$ and intra- and extrahepatic metastases

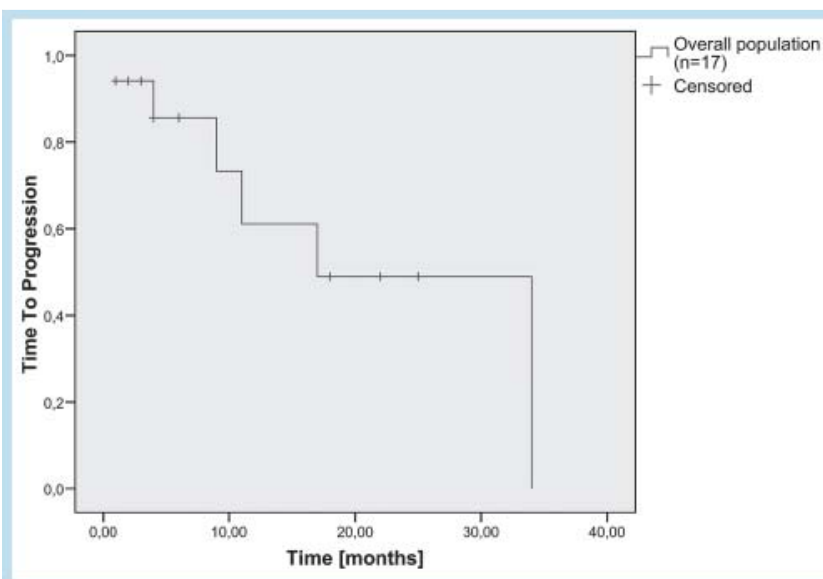

Fig. 5 Time to progression (TTP) after alcohol-lipiodol therapy (TAL). 6 patients showed tumor progression. 6 patients died without tumor progression. In 5 patients a treatment change took place due to an incomplete TAL. The median TTP of patients with tumor progression was 17 months.

$(n=1)$. In the remaining 3 patients, the primary tumor progressed either alone $(n=1)$ or in combination with intrahepatic metastases $(n=1)$ or intra- and extrahepatic $(n=1)$ metastases. Although the tumor progression in all 6 patients was initially a unilobar disease of the liver, both liver lobes were affected after tumor progression in 4 cases ( $\bullet$ Table 2 ).

\section{Lipiodol enhancement and tumor size}

The achieved lipiodol enhancement after TAL correlates inversely according to Spearman with the tumor diameter ( $p<0.001$; rank coefficient $\rho=-0.78$ ). Only high lipiodol enhancement ( $80 \%$ and higher) was achieved in tumors with a diameter of up to $7.5 \mathrm{~cm}$. Lower lipiodol enhancement was also seen in tumors $\geq 7.5 \mathrm{~cm}$ ( $\bullet$ Fig. 6 ). The cumulative survival of patients with HCC $\geq 7.5 \mathrm{~cm}$ ( $n=7$; median survival 3 months) was significantly $(\mathrm{p}=0.009)$ worse than in patients with HCC $<7.5 \mathrm{~cm} \quad(\mathrm{n}=10$, median survival 25 months; 0 Fig. 7).

\section{Discussion}

TAL was described for the first time at the start of the $1990 \mathrm{~s}$ [2]. Therapeutic emulsions with a high alcohol content (alcohol-lipiodol ratio 3:1) were used. The effectiveness of the 


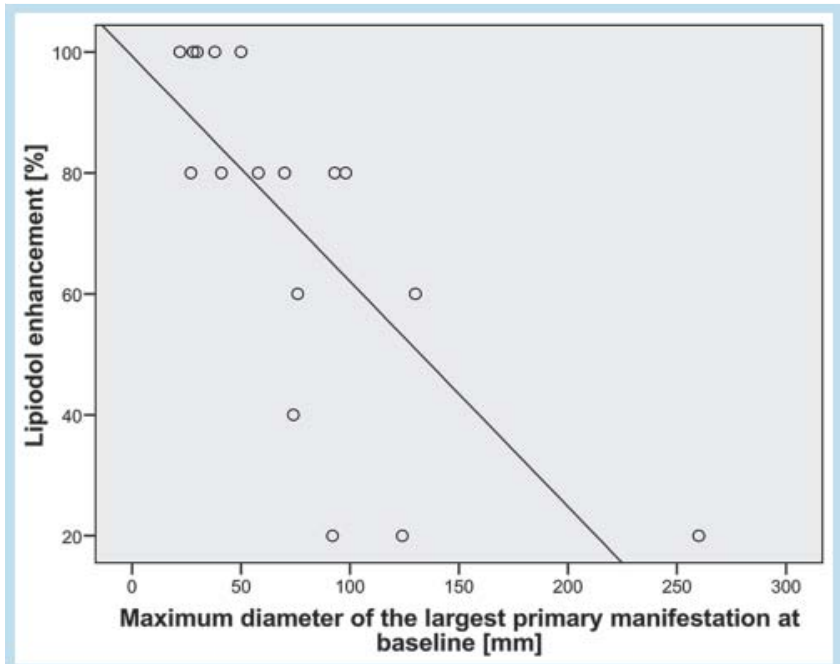

Fig. 6 Lipiodol enhancement after alcohol-lipiodol therapy. There is a significant, negative relationship between tumor size and lipiodol enhancement $(p<0.001)$. A large size was associated with a decreased level of reachable lipiodol enhancement of the tumor. For tumors with diameters up to $7.5 \mathrm{~cm}$, there were only high levels of lipiodol enhancement ( $80 \%$ and higher). Tumors with larger diameters partially showed lower levels of lipiodol enhancement (60\% and lower).

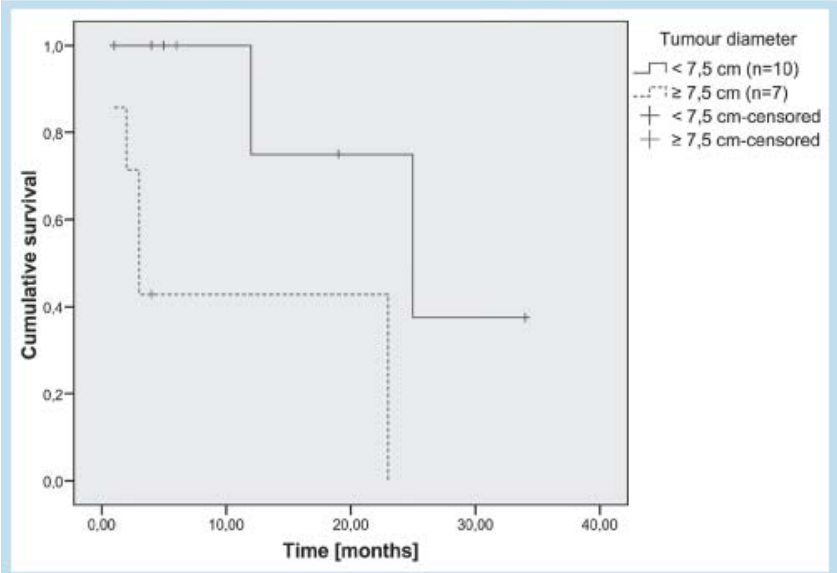

Fig. 7 Survival of patients with hepatocellular carcinoma (HCC) $<7.5 \mathrm{~cm}$ $(n=10)$ and $\geq 7.5 \mathrm{~cm}(n=7)$. Survival differs significantly $(p=0.009)$. The median survival of patients with $\mathrm{HCC}<7.5 \mathrm{~cm}$ was 25 months, and the median survival of patients with a larger HCC was 3 months. 2 patients were alive at the end of the TAL observation period (34 months) and survived a further 18 and 19 months, respectively, but they were censored because of a previous progression-associated therapy change.

technically similar TACE was examined and ultimately proven in approximately the same time period [6-8]. In contrast to the more well-known TACE, the relatively unknown TAL was largely abandoned. Incomplete tumor necrosis after TAL due to the high alcohol concentrations in the therapeutic emulsions was probably a contributing factor. As shown in later animal experiments [3], these high alcohol concentrations can cause early and thus premature vascular occlusion resulting in incomplete therapy.

Based on these results, TAL was later studied using lower alcohol concentrations and was performed in 77 patients with HCC with an average size of $5.2 \pm 3 \mathrm{~cm}(1.5-15 \mathrm{~cm})$
Table 4 Median survival after transarterial alcohol-lipiodol-therapy compared to two patient populations of literature with only supportive-care therapy (symptomatic therapy or therapy of complications, i. e. bleeding of gastroesophageal varices). Median survival is stated for each Okuda stage (Okuda et al., 1985 [9] and Yeung et al., 2005 [10]).

\begin{tabular}{|llll|}
\hline & our study & $\begin{array}{l}\text { Okuda et al., } \\
\mathbf{1 9 8 5}\end{array}$ & $\begin{array}{l}\text { Yeung et al., } \\
\mathbf{2 0 0 5}\end{array}$ \\
\hline Okuda stage I & $\begin{array}{l}23 \text { months } \\
(n=9)\end{array}$ & $\begin{array}{l}8.3 \text { months } \\
(n=33)\end{array}$ & $\begin{array}{l}5.1 \text { months } \\
(n=26)\end{array}$ \\
\hline Okuda stage II & $\begin{array}{l}12 \text { months } \\
(n=7)\end{array}$ & $\begin{array}{l}2 \text { months } \\
(n=134)\end{array}$ & $\begin{array}{l}2.7 \text { months } \\
(n=65)\end{array}$ \\
\hline Okuda stage III & $\begin{array}{l}3 \text { months } \\
(n=1)\end{array}$ & $\begin{array}{l}0.7 \text { months } \\
(n=62)\end{array}$ & $\begin{array}{l}1.0 \text { months } \\
(n=15)\end{array}$ \\
\hline
\end{tabular}

with $88.3 \%$ of the patients having Child-A cirrhosis and $11.7 \%$ of the patients having Child-B cirrhosis [4]. The median survival of 26.4 months was promising and the side effects and complications were low with the exception of a single case of irreversible decompensation of liver function ( $0.6 \%$ of interventions). Despite the more advanced tumor disease in our patient population with a larger average HCC size $(7.7 \pm 5.8 \mathrm{~cm} ; 2.2-26 \mathrm{~cm})$ and also advanced liver cirrhosis (Child-B in 4 patients (23.5\%) and Child-C in 1 patient $(6 \%)$ ), we achieved similarly good results in our patient population with an only slightly lower median survival of 23 months. A comparison to an HCC patient population treated only on a supportive care basis from the literature $[9,10]$ confirms the effectiveness of TAL. The median survival of our patients after TAL exceeded the survival of these patients treated only on a supportive care basis in every Okuda stage ( $\bullet$ Table 4$)$. The side effects were low: feeling of abdominal pressure during 2 of the 20 interventions, pain after 2 interventions, and fever after only 1 intervention in our patient population. Major complications were not observed. In contrast to Yu et al. (2008) [4], tumor infiltration of the portal vein in our patient population was not an exclusion criterion for the study and was present in 3 patients without decompensation of liver cirrhosis occurring after TAL. According to the current treatment recommendations of the AASLD (American Association for the Study of Liver Diseases) [11], TACE would not have been a treatment option in patients with portal vein infiltration and Child-C cirrhosis. In our experience, TAL is a safe and well tolerated therapy option for these patients and does not compromise already limited liver function. Later guidelines of the oncology guideline program of the Association of the Scientific Medical Societies in Germany, the German Cancer Society, and the German Cancer Aid permit TACE in the case of portal vein occlusion on a selective basis but only the terms "portal vein thrombosis" and "portal vein occlusion" are used so that the indication in the concrete case of portal vein occlusion due to tumor infiltration remains unclear [12]. The maximum survival of our patients with portal vein infiltration of 3 months was low but these 3 patients also had the largest HCC manifestations of our patient population with correspondingly poor lipiodol enhancement (० Fig. 6).

A reason for the good tolerability and the low complication rate of TAL, in particular in comparison to the technically similar TACE, is probably the superselective approach as well as the lack of chemotherapeutic substances. Even 
when using drug-loaded beads, outflow of chemotherapeutic agents cannot be completely prevented [13].

The superselective approach used in TAL without embolization of central liver vessels is also advantageous in another respect compared to TACE: Not only is impairment of liver function with irreversible liver failure rarer after TAL (3\% after TACE, $0.6 \%$ after TAL [4] or $0 \%$ in our patient population) but also subsequent therapies are not hindered by a prior TAL procedure. Both subsequent therapies after unsuccessful TAL (in 5 patients) as well as secondary therapies after tumor progression (in 3 patients) were able to be performed without problems and without restriction even in the case of another transarterial procedure. In contrast to TACE, the arterial accesses to the liver are not temporarily embolized in TAL but remain open. Even temporary occlusion of access vessels with degradable embolic agents can result in permanent occlusion due to damage to the vascular wall and can induce angiogenesis of complex tumorsupplying collaterals no longer accessible with angiography in any remaining vital tumor areas $[15,16]$. A loss of the option to perform subsequent therapy after TACE with temporary embolization has been described multiple times $[15,16]$. However, there is no risk of this after TAL $[4,15$, 16]. Under consideration of the high recurrence rate of HCC $[17,18]$ with interventional therapies often being required multiple times, an attempt should be made to retain the option to perform subsequent therapies since this aspect can be important for overall survival in many cases. Thus, primary therapeutic use of TAL can be superior to TACE.

Compared to SIRT, TAL is advantageous in patients with hepatopulmonary shunt because of the persistent feasibility of TAL. SIRT is known to be contraindicated in patients with a relevant pulmonary shunt due to the risk of pneumonitis [19].

Limitations of therapy effectiveness were seen in patients with very large HCC manifestations ( $\boldsymbol{O}$ Fig. 7 ), advanced tumor stages ( $\bullet$ Fig. 3 ), or portal vein infiltration. In the case of tumor diameters of $7.5 \mathrm{~cm}$ and larger, worse lipiodol enhancement was achieved ( $\bullet$ Fig. 6 ). The median survival in patients with HCC greater than or equal to $7.5 \mathrm{~cm}$ was 3 months vs. 25 months in patients with HCC smaller than $7.5 \mathrm{~cm}$ ( $\odot$ Fig. 7). The worse survival observed in our patient population for larger/more extensive HCC also applies to other methods, such as TACE [8] and SIRT [20]. Due to the pronounced heterogeneity of the HCC patient population, a comparison of the effectiveness of the individual treatment types is difficult. Meaningful, prospective, randomized, controlled studies with larger patient populations would be necessary but would hardly be feasible. If a decision in favor of transarterial therapy is made for such patients, TAL with a low alcohol concentration should be taken into consideration as a differential therapy. The method has minimal side effects, is effective and is very cost-effective compared to other treatment methods.

\section{Conclusion}

$\nabla$

Despite the advanced tumor stages with large, multifocal HCC and limited liver function of some of our patients, TAL was able to be performed safely, with few side effects, and effectively. Serious complications did not occur. Therefore,
TAL was a further feasible therapy option for patients who desired a therapy with minimal side effects due to advanced liver cirrhosis, who were not suitable for TACE due to advanced liver cirrhosis, or who were not suitable for RFA due to large, multifocal or diffuse-infiltrative HCC. Under consideration of the fact that the ability to implement subsequent therapies was not affected by TAL in any case in contrast to TACE and that multiple therapies are often necessary in the disease course due to the high recurrence rate in HCC patient populations, TAL is a potentially advantageous alternative to TACE in suitable cases. A meaningful comparison of TAL to other forms of therapy, e.g. TACE or SIRT, requires further prospective randomized studies with larger patient populations.

\section{Clinical relevance of the study}

TAL is a safe therapy option when other locoregional therapies (e.g. TACE) can no longer be performed due to advanced liver cirrhosis according to current therapy recommendations.

- TAL is a potential treatment option in cases in which other therapy options are no longer technically feasible (e.g. SIRT in pulmonary shunt or RFA in multifocal HCC or HCC $>5 \mathrm{~cm}$ ).

TAL did not result in worsening of the already typically limited liver function in any patient in our population and could be performed with minimal side effects.

- In contrast to TACE, TAL does not entail the risk of a loss of subsequent therapy options, which can be prognostically advantageous in light of the high recurrence rate in HCC patient populations with the frequent necessity for consecutive therapies/interventions.

\section{References}

1 Lencioni R. Loco-regional treatment of hepatocellular carcinoma. Hepatology 2010; 52: $762-773$

2 Park JH, Han JK, Chung JW et al. Superselective transcatheter arterial embolization with ethanol and iodized oil for hepatocellular carcinoma. J Vasc Interv Radiol 1993; 4: 333-339

3 Kan Z, Wallace S. Transcatheter liver lobar ablation: an experimental trial in an animal model. Eur Radiol 1997; 7: 1071-1075

$4 \mathrm{Yu}$ SC, Hui EP, Wong J et al. Transarterial ethanol ablation of hepatocellular carcinoma with lipiodol ethanol mixture: phase II study. J Vasc Interv Radiol 2008; 19: 95-103

5 Lencioni R, Llovet JM. Modified RECIST (mRECIST) assessment for hepatocellular carcinoma. Semin Liver Dis 2010; 30: 52-60

6 Groupe d'Etude et de Traitement du Carcinome Hépatocellulaire. A comparison of lipiodol chemoembolization and conservative treatment for unresectable hepatocellular carcinoma. N Engl J Med 1995; 332: $1256-1261$

7 Llovet JM, Real MI, Montaña X et al. Arterial embolisation or chemoembolisation versus symptomatic treatment in patients with unresectable hepatocellular carcinoma: a randomised controlled trial. Lancet 2002; 359: 1734 - 1739

8 Lo CM, Ngan H, Tso WK et al. Randomized controlled trial of transarterial lipiodol chemoembolization for unresectable hepatocellular carcinoma. Hepatology 2002; 35: 1164-1171

9 Okuda K, Ohtsuki T, Obata H et al. Natural History of Hepatocellular Carcinoma Cancer and Prognosis in Relation to Treatment. Cancer 1985; 56: $918-928$

10 Yeung YP, Lo CM, Liu CL et al. Natural history of untreated nonsurgical hepatocellular carcinoma. Am J Gastroenterol 2005; 100: 1995-2004 
11 Bruix J, Sherman M. Management of hepatocellular carcinoma: an update. Hepatology 2011; 53: 1020-1022

12 Leitlinienprogramm Onkologie (Deutsche Krebsgesellschaft, Deutsche Krebshilfe, AWMF): Diagnostik und Therapie des hepatozellulären Karzinoms, Langversion 1.0, AWMF Registrierungsnummer: 032-0530L. http://leitlinienprogramm-onkologie.de/ Leitlinien.7.0.html Zugegriffen: 27. Januar 2016

13 Kettenbach J, Stadler A, Katzler IV et al. Drug-loaded microspheres for the treatment of liver cancer: review of current results. Cardiovasc Intervent Radiol 2008; 31: 468-476

14 Chan AO, Yuen MF, Hui CKet al. A prospective study regarding the complications of transcatheter intraarterial lipiodol chemoembolization in patients with hepatocellular carcinoma. Cancer 2002; 94: 1747-1752

15 Ngan H, Lai CL, Fan ST et al. Treatment of inoperable hepatocellular carcinoma by transcatheter arterial chemoembolization using an emulsion of cisplatin in iodized oil and gelfoam. Clin Radiol 1993; 47: $315-320$
16 Ueno K, Miyazono N, Inoue H et al. Transcatheter arterial chemoembolization therapy using iodized oil for patients with unresectable hepatocellular carcinoma: evaluation of three kinds of regimens and analysis of prognostic factors. Cancer 2000; 88: $1574-1581$

17 Belghiti J, Panis $Y$, Farges $O$ et al. Intrahepatic recurrence after resection of hepatocellular carcinoma complicating cirrhosis. Ann Surg 1991; 214: $114-117$

18 Fuster J, García-Valdecasas JC, Grande L et al. Hepatocellular carcinoma and cirrhosis. Results of surgical treatment in a European series. Ann Surg 1996; 223: 297-302

19 Salem $R$, Thurston KG. Radioembolization with 90Yttrium microspheres: a state-of-the-art brachytherapy treatment for primary and secondary liver malignancies. Part 1: Technical and methodologic considerations. J Vasc Interv Radiol 2006; 17: 1251 -1278

20 Salem $R$, Lewandowski RJ, Kulik $L$ et al. Radioembolization Results in Longer Time-to-Progression and Reduced Toxicity Compared With Chemoembolization in Patients With Hepatocellular Carcinoma. Gastroenterology 2011; 140: 497-507 